\title{
Evaluating the Impact of Fires on the Environment
}

\author{
MARGARET SIMONSON MCNAMEE, PER BLOMQVIST, and PETRA ANDERSSON \\ SP Technical Research Institute of Sweden \\ Fire Technology \\ Box 857, SE-501 15 Borås, Sweden
}

\begin{abstract}
The impact of fires on humans and the environment has been the subject of investigation for decades. We have a variety of more or less well developed models to study the impact of fires on humans and even have several international standards categorising standardised approaches to quantifying the toxic potency of fire gas exposure. However, there is currently no standardised approach available to evaluate the environmental impact of fires and their countermeasures.

This paper will provide a summary of the work that the authors have conducted over the past 15 years on the development of different tools to investigate the environmental impact of fires, including Fire-LCA (life-cycle assessment) and Fire-CBA (cost benefit assessment). The benefit of a holistic approach will be discussed but also its limitations in light of data availability and quality, and the difficulties associated with interpreting the results. In particular, the development of a truly global approach to the modelling of the environmental impact of fires, incorporating such issues as toxicity, eco-toxicity and cost-benefit analysis into a traditional LCA model will be discussed. It is only through the development of such a tool that one can hope to be able to provide sound input to legislation in support of the development of environmentally sustainable fire safety.
\end{abstract}

This work will be presented against a backdrop of data concerning toxic and eco-toxic emissions from fires. Such data are a pre-requisite for modelling the environmental impact of fires and while much detailed data are now publicly available much still remains to be found - gaps in data will be identified and discussed.

KEYWORDS: environmental impact, toxicity, life-cycle assessment, cost benefit assessment.

\section{INTRODUCTION}

Awareness of the fact that large fires may present dramatic and persistent adverse effects on the environment has risen since the occurrence of numerous high impact incidents over the past 25 years, such as the Sandoz incident in November of 1986 when a chemical fire in an industrial warehouse near Basel in Switzerland laid waste to the Rhine [1]. Traditionally discussion of the environmental impact of fires has focused on the emissions that fires can cause both to the air, water and soil; but in recent years a new debate has arisen where the impact of chemicals on the environment and the precautionary principle have taken precedence [2]. In the wake of the political debate concerning potential exposure to chemicals in our environment, flame retardants, used to restrict the size and number of fires in products to which they are added, have also been questioned. In a debate article in Swedish press in the 1990s [3], a representative from the Swedish Civil Contingencies Agency (then the Swedish Rescue Services Agency) questioned the need for chemical additives in products in light of their unknown consequences on people and the environment. At that time no holistic tools were available that could make an objective assessment of the impact of flame retardants on the environment which prompted the development of a holistic LCA based model, the Fire-LCA model [4].

Several research projects have investigated emissions from fires since the 1980s. Initially many studies were qualitative and investigated which organic species could be expected in fire gases as most previous experience of the characterisation of combustion gases was from controlled combustion rather than fires, e.g. the groundbreaking work of Levin et al. at NIST [5-10]. It was not until the 1990s that large volumes of quantitative data concerning fire gas characterisation were first published to a great degree, such as that produced by SP [11-13]. SP Fire Technology started their work on detailed characterisation of fire gases in the 1990s with their participation in two pioneering EU-funded research programs: STEP [14] and TOXFIRE [15]. Both focused on combating the potential environmental impact of fires by forming a sound understanding of the potential magnitude of such emissions. In the STEP project a methodology for the measurement and characterisation of combustion gases from large-scale fires was developed and published. 
In the TOXFIRE project this methodology was applied to characterise the emissions from burning chemicals from medium-scale (of the order of $10 \mathrm{~kg}$ ) up to large-scale (of the order of $100 \mathrm{~kg}$ ). The main objective of the TOXFIRE project was to provide the basis for guidelines, e.g. for extinguishment, to be used by fire engineers and fire brigades when dealing with fires in chemical warehouses.

Early estimates of the magnitude of emissions from fires were made for Sweden in 1995 [16] and updated in 2001 [17]. These have been used as the basis for discussions of the magnitude of various emissions subsequently [18]. This early data also indicated that while numerous small chemical species (CO, HCN, $\mathrm{NO}_{\mathrm{x}}$, acid gases, etc) are significant from an acute toxicological point of view, emissions from fires of these species were not significant compared to other sources (e.g. the production of energy from combustion). Emissions of large organic species and particulates were, however, found to be of the same order of magnitude as other sources with documented environmental significance. Despite this work, no standardised method of assessing the environmental impact of fires was available by the turn of the $21^{\text {st }}$ century.

In recognition of the importance of the issue and the lack of a standardised approach, ISO TC 92/SC3 The effect of Fires on People and the Environment launched an initiative (a task force) in 2002 to investigate the potential for developing a standardised approach to assessing the environmental impact of fires. In 2006 this task force was used as the basis for a working group (WG6) on the environmental impact of fires, whose mission is to develop such a standardised approach to the environmental assessment of fires [19]. To date this group has produced one standard and several others are under development. The first standard, Guidelines for assessing the adverse environmental impact of fire effluents - Part I: General [20], is proposed as the first in a series of documents aimed at providing guidance on which species are important in terms of the environmental impact of fires and how these should be quantified and assessed. Much work remains to be done but a beginning has been made.

In lieu of an internationally agreed standardised approach to the assessment of the environmental impact of fires, several holistic tools have been developed and applied to a number of case studies with a focus on assessing the impact of flame retardant choices in consumer products [21-25]. As will be outlined in this paper, the models provide some of the answers but leave many questions still unanswered. More work is needed on the development of global assessment tools to be able to weigh countervailing environmental emissions and constraints against each other to optimise the multi-facetted nature of the interaction between fires (and chemicals or methods used to avoid or mitigate them) and the environment.

This paper will try to provide some insight into the present state-of-the-art concerning holistic modelling tools and illustrate their usefulness and short-comings through their application to a specific case study: the comparison between a TV set with relatively low fire performance (a non-flame retarded (non-FR) TV), and one with a relatively high level of fire performance (an FR TV).

\section{FIRE EMISSIONS}

Fires produce a complex cocktail of effluents, all with varying modes of action and longevity, toxicity and eco-toxicity. Typically the impact of fire emissions can be divided into acute and long term effects. In terms of the environmental impact of fire effluents, long term effects are often more important than acute effects. Traditionally, carbon monoxide (CO) is recognised as the main acute toxicant in fires [26] although numerous other gases are acknowledged as potentially important in determining the outcome of any given fire exposure. Hydrogen cyanide (HCN), elevated levels of carbon dioxide $\left(\mathrm{CO}_{2}\right)$ and oxygen vitiation are also important in their contribution to the asphyxiating characteristics of smoke gases upon direct exposure. Other components in smoke gases that cause sensory irritation to eyes and the upper respiratory tract include acid gases produced from the combustion of halogen-containing materials (where hydrogen chloride, $\mathrm{HCl}$, is the most common), and a variety of organic compounds, such as: formaldehyde, acrolein and isocyanates. Irritant gases may have their greatest influence in reducing the speed of egress in the evacuation of people from a fire. Models for assessment of the effects of chemical compounds with an acute effect on people are available in ISO 13571 [27].

In contrast, large organic species, such as dioxins or polycyclic aromatic hydrocarbons (PAHs) are those species which are thought to have the greatest environmental impact [12]. A guideline document for the assessment of the environmental impact from fires has been developed in ISO/TC92 SC3/WG6. This document presents emission pathways and species of interest from an eco-toxicological point of view. 
There are, however, no standards available for the quantification of the effect from fires on the environment. The interaction between a fire and its surroundings (or environment) is illustrated in Fig. 1. This figure clearly shows that there are a number of different emission pathways that allow a fire to impact on the environment. The effect of these emissions depends on the transfer mechanism (i.e., emission of gaseous species to the atmosphere, or emissions to the terrestrial or aquatic environment), the susceptibility of the recipient, and on the specific species [28].

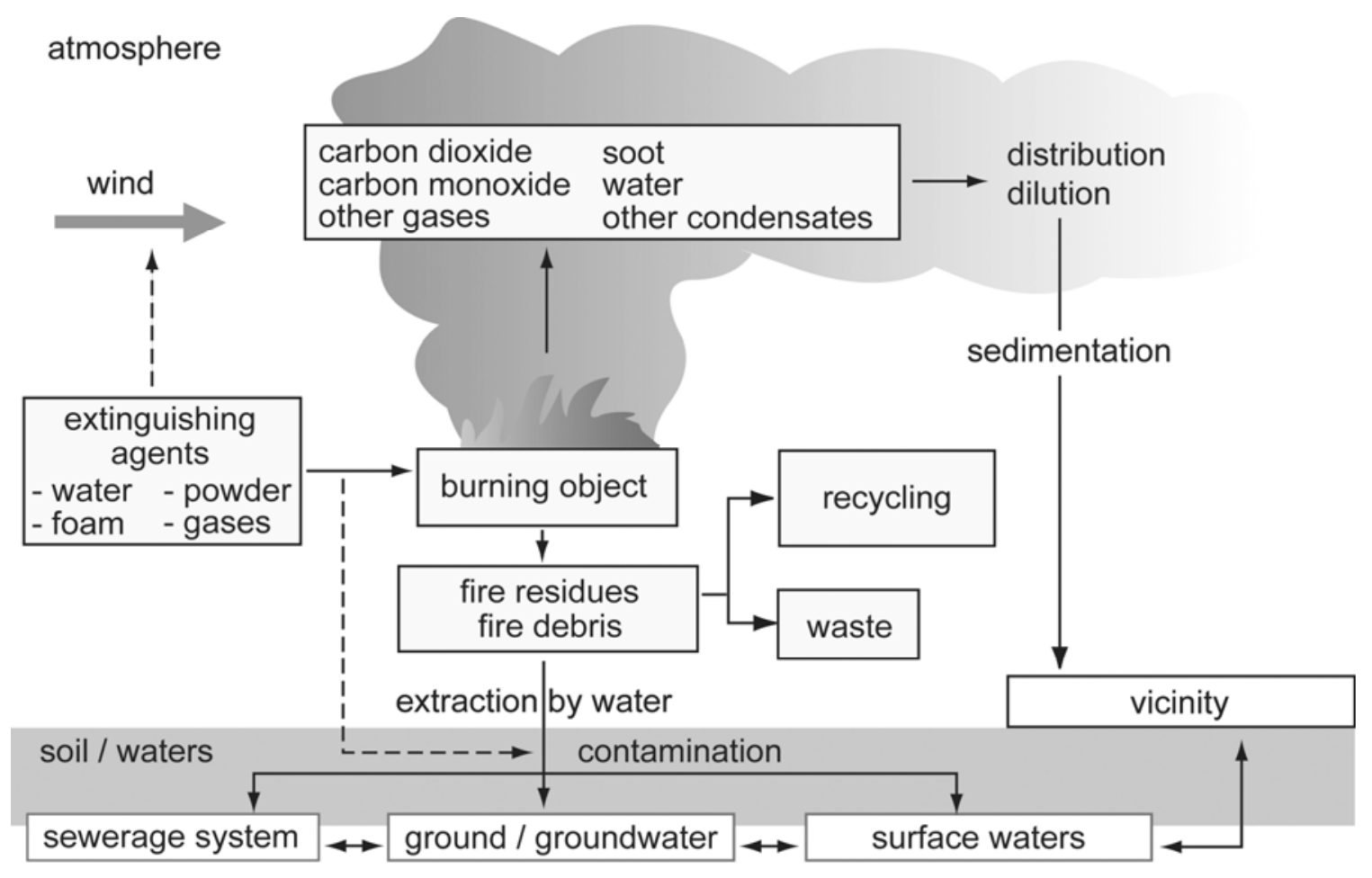

Fig. 1. Emission pathways (based on Ref. [28]).

The next section of this paper deals with different models that have been developed in an effort to quantify (at least to a certain degree) the environmental impact of fires. In order for these models to give relevant answers concerning the impact of various emissions from different sources it is imperative that relevant data are available from the different potential sources of these emissions. Numerous papers concerning emissions from fires have been published in the open literature and can be used as input to an assessment of the environmental impact of fires, Refs. [11-13,29-31] just to name a few. A recent book, however, has compiled a significant amount of the fire emission (gaseous) data which are presently available [32]. In those cases where such data are available it is generally most detailed for gaseous emissions, with relatively less information available concerning emissions to the aquatic or terrestrial environment.

\section{ASSSESSMENT METHODOLOGIES}

Numerous environmental assessment methodologies exist ranging from full LCA tools such as those that we have build our Fire-LCA and Fire-CBA methodology on, to less detailed types of environmental assessment tools (e.g. EPD). Traditionally these tools assume an incident free life-cycle of the product or process being evaluated. This means that in the case of a traditional tool, the function of, e.g., a flame retardant or an extinguishing medium in terms of a potential reduction in the number and size of fires is not included. The only thing that is included is the environmental cost in terms of resource use and emissions during the entire life-cycle. This implies that any chemical additive is by definition only an additional environmental impact without the inclusion of mitigating circumstances for its inclusion by an overall change in the way the product interacts with the environment, e.g. a change in the overall production of emissions in fires. 
In response to the limitations of traditional environmental assessment tools, the Fire-LCA model was first developed in 1995. The aim was to develop a tool that could be used for comparing the environmental impact of different fire performance legislations. LCA was chosen as the basis for the development as this is a widely used tool and sufficiently sophisticated to include factors like the effect of the mitigation of fires. It soon became apparent, however, that this model also has its limitations and the Fire-CBA model was developed to address some of these limitations. This section of the paper presents both the basis of a traditional LCA, the Fire-LCA model and the Fire-CBA model.

\section{Traditional LCA}

International standards for LCA methodology have been prepared by the International Organization for Standardization (ISO). The following standards are available today:

- Principles and framework (ISO 14040) [33].

- Requirements and guidelines (ISO 14044) [34].

ISO 14040:2006 and ISO 14044:2006 replace the previous standards (ISO 14040:1997 [35], ISO 14041:1999 [36], ISO 14042:2000 [37] and ISO 14043:2000 [38]). The new editions have been updated to improve readability, while leaving the requirements and technical content unaffected, except for errors and inconsistencies.

ISO 14040:2006, Environmental management - Life cycle assessment - Principles and framework, provides a clear overview of the practice, applications and limitations of LCA to a broad range of potential users and stakeholders, including those with a limited knowledge of life-cycle assessment. ISO 14044:2006, Environmental management - Life cycle assessment - Requirements and guidelines, is designed for the preparation of, conduction of, and critical review of, life-cycle inventory analysis. It also provides guidance on the impact assessment phase of LCA and on the interpretation of LCA results, as well as the nature and quality of the data collected.

Generally the method can be divided into three basic steps with the methodology for the first two steps relatively well established while the third step (impact assessment) is more difficult and controversial. The first two steps are usually referred to as the life cycle inventory (LCI) and can be applied separately without the following impact assessment. In addition to the different steps in the procedure there can also be an interpretation phase. The three basic steps are shown in Fig. 2. Each of these steps is dealt with separately below.

The goal and scope definition consists of defining the study's purpose, its scope, system boundaries, establishing the functional unit, and establishing a strategy for data collection and quality assurance within the study. Any product or service needs to be represented as a system in the inventory analysis methodology. A system is defined as a collection of materially- and energetically-connected processes (e.g. fuel extraction processes, manufacturing processes or transport processes), which perform some defined function. The system is separated from its surroundings by a system boundary. The entire region outside the boundary is known as the system environment.

The functional unit is the measure of performance, which the system delivers. The functional unit describes the main function(s) of the system(s) and is therefore a relevant and well-defined measure of the system. The functional unit has to be clearly defined, measurable, and relevant to input and output data. 


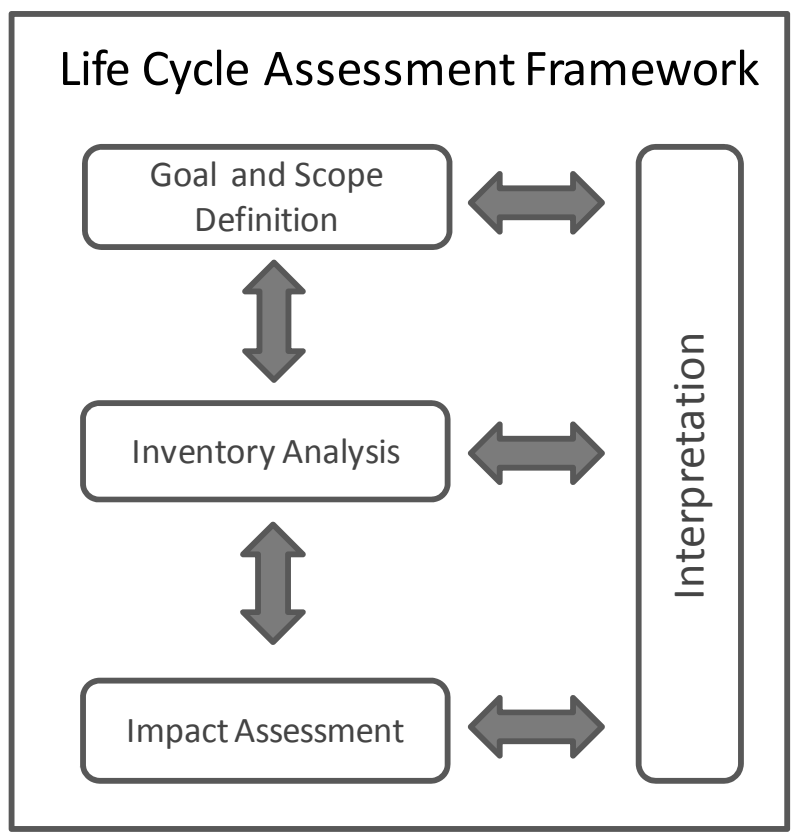

Fig. 2. The main phases of an LCA according to the ISO standard [33].

In the inventory analysis the material and energy flows are quantified. The system consists of several processes or activities, e.g., crude material extraction, transport, production, waste handling, and in the Fire-LCA model, fires. The different processes in the system are then quantified in terms of energy use, resource use, emissions etc. Each sub-process has its own performance unit and several in- and outflows. The processes are then linked together to form the system to analyse. The final result of the model is the sum of all in- and outflows calculated per functional unit for the entire system.

The most difficult part and also the most controversial part of an LCA is the impact assessment. So far, no standard procedure exists for the implementation of an entire impact assessment. However, the ISO standard covers the so-called life cycle impact assessment (LCIA) [35], where different impact categories are used and recommendations are given for life cycle interpretation [36]. Transparency of the LCA model is, however, important and inventory data must also be available in addition to aggregated data.

\section{Fire-LCA Methodology}

In a conventional LCA the risk factors for accidental spills are excluded. The Fire-LCA methodology differs from the traditional LCA approach in that provisions have been made to include the impact of fires in the total life-cycle of the functional unit. Schematically the LCA model proposed for a Fire-LCA can be illustrated as in Fig. 3.

During the lifetime of the products to be analysed, it is assumed that some products will be involved in different types of fires. The Fire-LCA model includes modules to describe the fire behaviour for the different types of fires. Fire statistics are used to quantify the amount of materials involved in the different types of fires. In addition, the model should include modules for handling the production of replacement materials that is needed due to the shortening of lifetime that the fires have caused. If possible the model should also include modules for the handling of the fire extinguishing process and the decontamination process. 


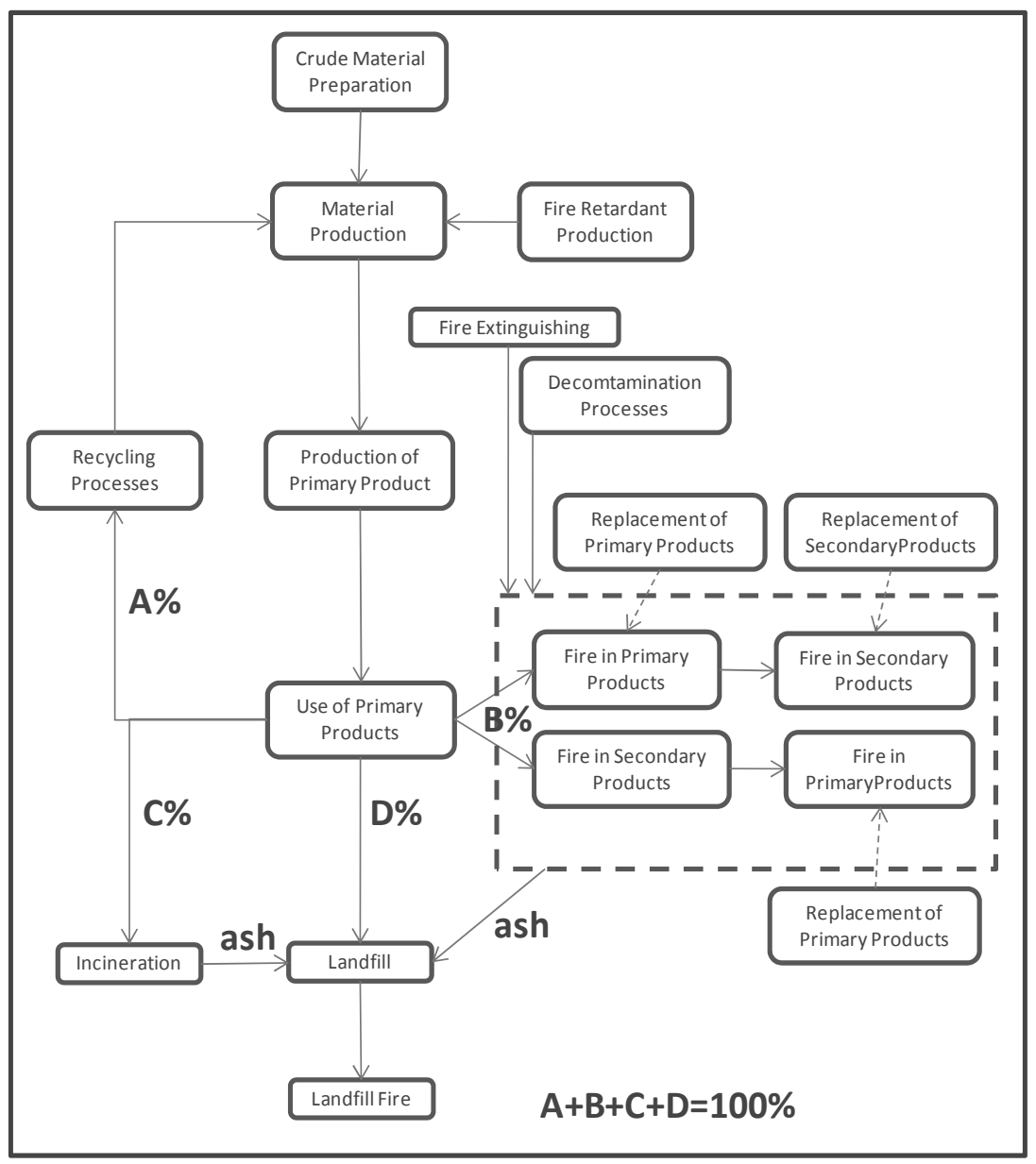

Fig. 3. Schematic representation of the Fire-LCA model [21].

The main parts to be included in the model are:

- Production of materials and fuels to be used in the product production.

- Production of the fire protection system.

- Production of the product to be analysed (defined as the primary product).

- Use of the primary product.

- Waste handling of the primary product including:

- Landfill

- Incineration

- Recycling

- Fire modules describing:

- Fires starting in the primary product and spreading to surrounding products (defined as secondary products). These fires are called primary fires. Fires starting in the secondary product and spreading to the primary product. These fires are called secondary fires.

- Wastes from fire activities including demolition, decontamination, landfill, incineration, recycling

- Replacement of primary products lost in both primary and secondary fires. Replacement of secondary products that have been lost in primary fires spreading to secondary products.

- Fire extinguishing activities.

- Landfill fires in the landfilled materials. 
This represents a comprehensive list of the processes involved in fires. In practice it is generally not feasible to include all of the above activities.

The intermediate output from a Fire-LCA model is a body of data concerning emissions to air, water and soil, energy and materials use, etc. There is, however, no well defined or standardised way to interpret this data and make an assessment of the importance of one emission over another, or of the use of resources compared to their benefit. This makes it difficult to make a comparison between the different alternatives.

\section{Fire-CBA}

The holistic, LCA-based, approach described above is also the basis for the Fire-CBA model [39]. In a traditional Fire-LCA one focuses on the emissions and energy requirements for each module. The FireCBA model, however, focuses on the costs (positive and negative) associated with the product life-cycle. In order to minimise the input requirements of the Fire-CBA, however, the Fire-CBA model focuses on the costs and benefits associated with choices made to produce a high level of fire safety throughout the FireLCA in purely financial terms. This focus on costs also facilitates the comparison between the different alternatives (scenarios) as the result is purely a net cost or benefit rather than a large number of emissions or resource uses.

The costs associated with the functional unit include such things as raw material for the production, possible costs associated with the use of the product and, finally, costs associated with its end-of-life, e.g. disposal or inclusion in a fire. In the Fire-CBA model, the base-line is defined as the choice of a minimum level of fire safety and the cost and benefit of an incremental increase in fire safety only is calculated. The costs, associated with production and use of the base-line product, are equivalent and therefore excluded from the overall calculation. This reduces the data collection requirement significantly, but provides only the incremental cost and benefit which is needed for sound decision making, not the absolute costs and benefits associated with each individual product.

Table 1. Collation of requirements for Fire-CBA per module [39].

\begin{tabular}{|l|l|}
\hline Module & Comment \\
\hline Production & $\begin{array}{l}\text { Any additional costs associated with production should be included in this part of } \\
\text { the CBA. In some cases the use of alternative materials can require significant } \\
\text { investments by industry which should be included in the cost. }\end{array}$ \\
\hline Use & $\begin{array}{l}\text { The difference assumed in the Fire-CBA does not impact on the costs associated } \\
\text { with the use and this will not be included. }\end{array}$ \\
\hline Transport & $\begin{array}{l}\text { As for the use, the costs associated with transportation of the functional unit } \\
\text { would not be expected to change through the introduction of flame retardants or } \\
\text { other fire mitigation measures. }\end{array}$ \\
\hline Destruction & $\begin{array}{l}\text { Additional costs associated with specific destruction plans could be included in } \\
\text { this module, e.g. specific cost programs related to the end-of-life destruction of } \\
\text { consumer products. Alternatively one could consider a worst case scenario with a } \\
\text { dedicated, isolated stream destruction of materials containing 'hazardous' } \\
\text { chemicals and the cost associated with this. }\end{array}$ \\
\hline Chemical Exposure & $\begin{array}{l}\text { The cost of extinguishment, sanitation, treatment of injuries and possible deaths } \\
\text { should be included in the cost of fires. Indeed one of the major benefits of the use } \\
\text { of a high level of fire safety is the avoidance of fires, reduction in the size of fires } \\
\text { that occur and reduction in injuries and loss of lives. }\end{array}$ \\
\hline $\begin{array}{l}\text { This is not strictly a 'module' but related to exposure which can occur connected } \\
\text { to chemicals throughout the life-cycle of the product. In the Fire-CBA model this } \\
\text { is focused on exposure to flame retardants. }\end{array}$ \\
\hline
\end{tabular}

Table 1 shows the various parts of the full life-cycle and whether the costs and benefits need to be calculated to obtain a full understanding of the incremental change caused by the choice of level of fire safety. 
One of the most important issues which must be resolved when conducting a cost-benefit analysis is associated with the value of a life and whether this should be variable based on the age of the life lost. The use of CBA has become more accepted in the realm of environmental and other health and safety related legislation. The primary benefit of many important environmental requirements, as determined by the monetary value of the CBA, is the human lives that are saved. Thus, in determining whether a particular regulation can be justified, the central issues often revolve around the value assigned to the lives that would be saved by a specific program [40]. While the concept of placing a value on mortality can be seen as immoral [41] it is a necessary prerequisite of any CBA. In recognition of this a great deal has been learned about value of a statistical life (VSL) over the past 30 years [42].

The literature contains a wide range of proposed VSLs and Table 2 contains a summary of the various VSLs that were found during the development of the Fire-CBA model. The values are based on a willingness to pay (WTP) philosophy [42]. Situations in which risk is, at least partially, a matter of choice provide opportunities to analyse behaviour and estimate the WTP for risk reductions (e.g., through a higher price for a product) or the willingness to accept (WTA) compensation for risk increments (e.g., reduction in the price of a product, or increase in payment for a risk filled occupation).

While the values included in Table 2 correspond to the VSL for a risk averted immediately, a life-cycle approach must take into account the fact that averting behaviour can be used now to change mortality risks in the future. This is generally done through discounting of future lives relative to present lives. In 1980, the US EPA Office of Management and Budget (OMB) strongly urged discounting the value of human lives over the period of latency of the harm [40]. At that time they recommended a discount rate of $10 \%$ but more recent CBAs published by the US EPA use a more moderate discount rate of $3 \%$ [43].

Table 2. VSLs from a variety of studies [39].

\begin{tabular}{|l|l|l|}
\hline VSL (year 2000, million US\$) & Behaviour and trade-off & Reference \\
\hline$\$ 1,7$ & $\begin{array}{l}\text { Speeds and fatalities on interstate highways } \\
\text { with higher speed limits }\end{array}$ & $\begin{array}{l}\text { Ashenfelter and } \\
\text { Greenstone (2002) [44] }\end{array}$ \\
\hline $\begin{array}{l}\text { Adult: } \$ 4,3 \\
\text { Child: } 3-9: \$ 2,9 ; 10-14: \$ 2,8\end{array}$ & $\begin{array}{l}\text { Based on bicycle helmet use with fatality } \\
\text { risk reductions and costs }\end{array}$ & $\begin{array}{l}\text { Jenkins, Owens and } \\
\text { Wiggins (2001) [45] }\end{array}$ \\
\hline $\begin{array}{l}\text { Adult: } \$ 2,8-4,6 \\
\text { Child: }<5: \$ 3,7-6,0 \\
\text { Motorcyclist: } \$ 1,7-2,8\end{array}$ & $\begin{array}{l}\text { Based on car seat best use with fatality risk } \\
\text { reductions and time and disutility costs }\end{array}$ & $\begin{array}{l}\text { Blomquist, Miller and } \\
\text { Levy (1996) [46] }\end{array}$ \\
\hline Child, $<5: \$ 0,8$ & $\begin{array}{l}\text { Child safety seat use with fatality risk } \\
\text { reductions with time and money costs }\end{array}$ & $\begin{array}{l}\text { Carlin and Sandy } \\
\text { (1991) [47] }\end{array}$ \\
\hline $\begin{array}{l}\text { Adult: } \$ 7,2 \\
\text { Child: } \$ 7,3\end{array}$ & $\begin{array}{l}\text { Hedonic analysis of motor vehicle prices } \\
\text { with fatality risks }\end{array}$ & $\begin{array}{l}\text { Mount et al. (2001) } \\
\text { [48] }\end{array}$ \\
\hline$\$ 3,8-\$ 5,4$ & $\begin{array}{l}\text { Hedonic analysis of car prices with fatality } \\
\text { risk }\end{array}$ & $\begin{array}{l}\text { Dreyfus and Viscusi } \\
\text { (1995) [49] }\end{array}$ \\
\hline$\$ 5,3$ & $\begin{array}{l}\text { Hedonic analysis of car prices with fatality } \\
\text { risk }\end{array}$ & $\begin{array}{l}\text { Atkinson and } \\
\text { Halvorsen (1990) [50] }\end{array}$ \\
\hline$\$ 4,7^{\text {a }}$ & $\begin{array}{l}\text { Hedonic analysis of housing prices with } \\
\text { fatality risk near Superfund Sites }\end{array}$ & $\begin{array}{l}\text { Gayer, Hamilton and } \\
\text { Viscusi (2000) [51] }\end{array}$ \\
\hline$\$ 5$ & $\begin{array}{l}\text { Average value used by the CPSC when } \\
\text { conducting CBAs as part of their rule } \\
\text { making process. }\end{array}$ & CPSC report 2005 [43] \\
\hline
\end{tabular}

${ }^{\mathrm{a}}$ Value for a statistical cancer case.

\section{MODEL APPLICATION TO A TV CASE STUDY}

\section{Fire-LCA}

Results from an LCA study can be presented in numerous ways. Typically LCA studies are conducted in a comparative manner with one model of the functional unit being compared to another. In the Fire-LCA studies conducted to date the model has been used in three ways, i.e., to: 
- compare two versions of the same product with essentially the same components and materials, but with different fire performance,

- compare two versions of a product with the same overall fire performance but different construction materials,

- determine the significance of fire as an parameter of environmental impact relative to a traditional LCA, i.e. a comparison between a traditional LCA and a Fire-LCA.

In the first case one can draw conclusions concerning the environmental impact of choosing a high level of fire performance over a low level of fire performance. In the second case one can draw conclusions concerning the relative environmental impact of the product depending on which materials are used in the product construction, when the environmental impact of fires is included in the overall LCA treatment. Naturally in both cases the model is open to the investigation of different scenarios within the same general comparison, e.g. in terms of comparing different end-of-life scenarios or different modes of production. In the third case it was possible to identify the environmental burden from fires and possible benefit of implementing fire protection.

Three full Fire-LCA studies have been conducted to date, i.e. a Furniture Case Study [52], a Cable Case study [53,54] and a TV Case Study [55]. Further, a partial Fire-LCA of a warehouse has been conducted [4], as well as the use of the Fire-LCA model as a decision making tool in tank fire protection [56]. These Fire-LCA studies have included facets of all three types of comparison. In the case of the TV Case Study, two different versions of the same product were compared. In the study the only ostensible difference between the two versions is their fire performance. In the Furniture Case Study, three different versions of the same sofa were compared. One version had low fire performance while the other two had a high level of fire performance, achieved by using two different flame retardants. Finally in the Cables Case Study, similar levels of fire safety were achieved using different material and compared.

Nearly all life-cycle assessments contain a large quantity of data. Usually it is neither possible nor necessary to analyse all the different parameters in a study. It is, therefore, of great importance to select and analyse key parameters. The selection of parameters for further analysis should focus on two different criteria. Firstly, the parameter must be well represented in the system with high quality data and few data gaps; secondly, data of direct relevance for the fire aspect should be placed in focus when using the FireLCA model. Should the data of direct relevance for the fire aspects not exhibit major differences between the different scenarios, one could interpret the results to mean that the fire part of the model does not offer any additional insight over those of a traditional LCA, and the uncertainties in the fire part of the model should be removed by reverting back to a traditional LCA treatment.

As the assessment methodologies are illustrated using the results from a TV Case Study [55], some illustrative results are presented showing that typical emissions data are relevant as input when modelling the environmental impact of fires. One should, however, emphasise that when conducting tests for fire gas characterisation it is important to quantify a broad range of different emissions as these species are important when establishing the significance of fire emissions relative to other sources. Therefore, despite the fact that the emission of $\mathrm{CO}_{2}$ from fires, e.g. has been ruled out as environmentally significant, it is important to quantify it as a fire emission because this ensures that the LCA input is as complete as possible. Full details of how the experiments were run from which the data were collected are given elsewhere [55] and will not be repeated here. Table 3 provides basic details concerning the combustible content in the TV sets.

Table 3. Combustible material in TV sets used in the Fire-LCA TV Case Study [55].

\begin{tabular}{|l|l|l|}
\hline Product & Non-FR TV & FR TV \\
\hline Total weight & $31.4 \mathrm{~kg}$ & $33.6 \mathrm{~kg}$ \\
\hline $\begin{array}{l}\text { Combustible } \\
\text { weight (approx.) }\end{array}$ & $7.1 \mathrm{~kg}$ & $6.5 \mathrm{~kg}$ \\
\hline
\end{tabular}

${ }^{\mathrm{a}}$ Mainly from the polystyrene housing with small contributions from the circuit boards and wiring. 
In most cases large organic species are measured using cumulative sampling which means that single point data are available for the entire measurement period. To illustrate the type of emissions data that can be obtained from fire experiments and that are relevant as input to an LCA, PAH and emissions of flame retardants (to air) are summarised in Table 4.

Table 4. Yields PAH (g/kg burned material) and deca-BDE (mg/kg burned material) from the non-FR and FR TV experiments from the Fire-LCA TV Case Study [55].

\begin{tabular}{|l|c|c|}
\hline Species & Swedish TV & US TV \\
\hline Naphthalene & 1.48 & 4.78 \\
\hline Acenaphthalene & 0.84 & 0.29 \\
\hline Acenaphthene & 0.05 & 0.04 \\
\hline Fluorene & 0.29 & 0.22 \\
\hline Phenanthrene & 1.56 & 2.92 \\
\hline Anthracene & 0.18 & 0.07 \\
\hline Fluoranthrene & 0.32 & 0.81 \\
\hline Pyrene & 0.17 & 0.04 \\
\hline Benzo(a)fluorene & 0.09 & 0.18 \\
\hline Benzo(b)fluorene & 0.08 & 0.09 \\
\hline Benzo(a)anthracene & 0.10 & 0.25 \\
\hline Chrysene & 0.25 & 0.97 \\
\hline Benzo(b)fluoranthene & 0.20 & 0.47 \\
\hline Benzo(k)fluoranthene & 0.04 & 0.09 \\
\hline Benzo(e)pyrene & 0.06 & 0.13 \\
\hline Benzo(a)pyrene & 0.06 & 0.09 \\
\hline Perylene & 0.01 & 0.01 \\
\hline Indeno(1,2,3-c,d)pyrene & 0.06 & 0.14 \\
\hline Benzo(g,h,i)perylene & 0.04 & 0.07 \\
\hline Dibenzo(a,h)anthracene & 0.03 & 0.14 \\
\hline Coronene & 0.01 & 0.02 \\
\hline deca-BDE & $<0.005$ & 8.1 \\
\hline
\end{tabular}

Fig. 4 shows selected results of a comparison between emissions from the life-cycle of a flame retarded TV and a non-flame retarded TV for various species using the Fire-LCA model. In this figure a modern scenario ('today') and a future scenario are compared. The assumptions forming the basis for each scenario are given in Table 5.

In both the 'today' and the 'future' scenarios, one can see that fires are an insignificant source of carbon dioxide, which is quite expected as carbon dioxide is the major end product for emission of carbon irrespectively of the fate of the TV. However, fires constitute a significant source of PAH from TVs throughout their life-cycle. This aspect would be lost in a traditional LCA analysis which could lead to incorrect conclusions concerning emissions of PAH from a flame retarded or non-flame retarded TV. This can be said to be true of all major organic species whose emissions are minimised from controlled combustion, but that are produced to a large degree in fires. Finally the results for emission of deca-BDE are also presented. Naturally emissions of deca-BDE dominate from the FR TV.

Table 5. Waste handling scenarios for the TV sets in the models [55].

\begin{tabular}{|l|c|c|}
\hline Activity & Waste handling of 'today' & 'Future' waste handling \\
\hline TV sets to incineration & $1 \%$ & $1 \%$ \\
\hline TV sets to disassembly (for recycling) & $2 \%$ & $89 \%$ \\
\hline TV fire (failed TV sets to incineration) & $1 \%$ & $1 \%$ \\
\hline TV sets to landfill & $\begin{array}{c}\text { Remaining part except TV } \\
\text { sets to fire }\end{array}$ & $\begin{array}{c}\text { Remaining part except TV } \\
\text { sets to fire }\end{array}$ \\
\hline
\end{tabular}




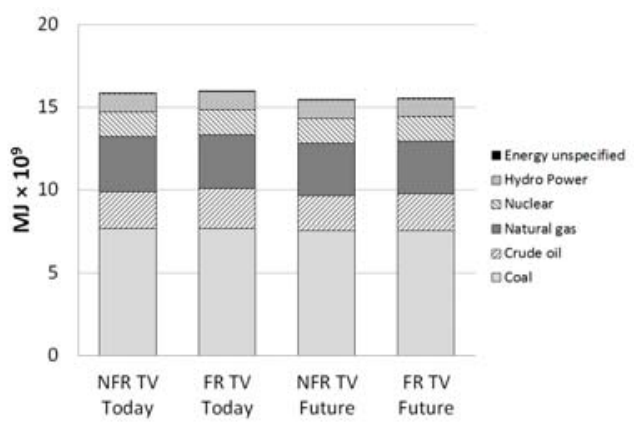

(a)

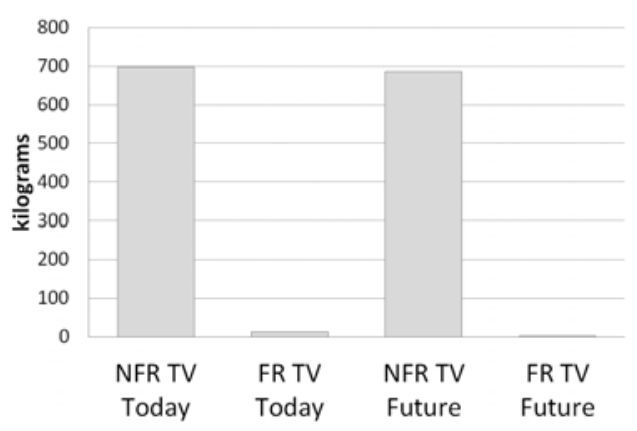

(c)

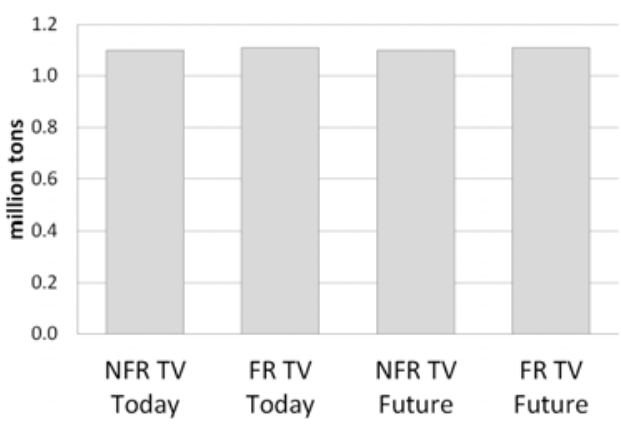

(b)

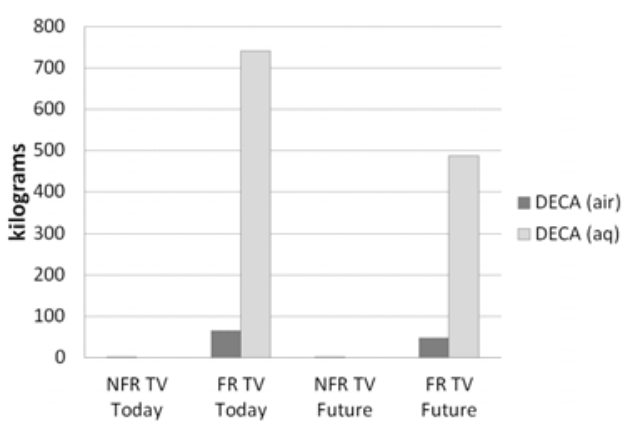

(d)

Fig. 4. (a) Energy use; (b) carbon dioxide emissions; (c) PAH emissions; (d) deca-BDE emissions to air and water per million TV sets from the Fire-LCA TV Case Study [55].

The Fire-LCA model has one major drawback that even a traditional LCA model suffers from; it is difficult to weigh an emission saved (in this case PAH) against an emission gained (i.e., deca-BDE). This was one of the reasons to establish the Fire-CBA model, in an effort to investigate the cost-benefit relationship when the cost of a fire is included in the equation.

\section{Fire-CBA}

While the Fire-LCA model does provide interesting results concerning the emissions from products where their fire performance is taken into account, no information is included concerning the costs or benefits of the choices made, e.g. to ensure a high level of fire safety. A number of important costs must be included, to take into account the financial cost and benefit of any given proposed legislation. In the case of the application presented above, the use of a specific flame retardant (deca-BDE) to reach a high level of fire safety was studied. Both TV sets were assumed to be essentially equivalent in terms of their chemical content with the exception of deca-BDE. Therefore, exposure to other chemical compounds in the TV set was not considered as this exposure would be the same for both TV sets. Both TV sets were compliant with regulations in Europe but only the TV containing deca-BDE in the outer enclosure was compliant in the USA.

A full analysis of the input for the only Fire-CBA study that has been conducted to date is available in Ref. [39]. Table 6 contains a summary of the different scenarios chosen for the study while Table 7 contains a summary of the data used in the Fire-CBA calculations.

In all the scenarios, a 10 year life-cycle was assumed for the TV sets. This is important as it means that $10 \%$ of the TV sets are replaced each year and benefits and costs are cumulative over the full 10 year lifecycle. Three different discounting scenarios were tested $(0 \%, 3 \%$ and $10 \%)$ to illustrate the significance of the discounting rate on the impact of future lives saved or costs incurred. Two costs of disposal were used to illustrate the significance of this cost in the analysis. These two values (US $\$ 1$ and US $\$ 13,3$ ) were chosen to represent extremes present in the EU. In many cases there is no direct cost to consumers for 
recycling, which would significantly increase the impact of the overall benefit of the avoided fires, fatalities and injuries.

Finally, the capital cost of fires (for replacement of property) is difficult to determine and has been included to a varying degree in the various scenarios. In the most conservative case the capital cost of fires has not been included. This is true of Scenarios 1-3. Scenarios 4 and 6-8 include the capital cost to replace full house fires to the degree suggested in the Fire-LCA TV Case Study, while Scenario 5 includes a nominal cost per fire for all TV fires, again based on the data available in the Fire-LCA TV Case Study. In this case the full house fires are included indirectly as one of many types of fires.

Table 8 contains a summary of the costs calculated for each scenario using the Fire-CBA model. Clearly this application of the Fire-CBA model is skewed towards the benefit of avoiding a fire, which can potentially result in significant injury or death as there is presently no indication of a cost in terms of injury or death due to exposure to deca-BDE.

Table 6. Summary of scenarios for the CBA calculation. All scenarios assume one million FR TV sets. Entire data can be found in Ref. [39].

\begin{tabular}{|l|l|l|l|l|l|}
\hline Scenario & $\begin{array}{l}\text { Life-cycle } \\
\text { (yrs) }\end{array}$ & Discounting & $\begin{array}{c}\text { Cost of } \\
\text { disposal }^{\mathbf{a}}\end{array}$ & $\begin{array}{l}\text { Cost of house } \\
\text { fires included }\end{array}$ & $\begin{array}{l}\text { Insurance costs } \\
\text { included }\end{array}$ \\
\hline 1 & 10 & No discount & US $\$ 1$ & No & No \\
\hline 2 & 10 & $3 \%$ & US $\$ 1$ & No & No \\
\hline 3 & 10 & $3 \%$ & US $\$ 13,3$ & No & No \\
\hline 4 & 10 & $3 \%$ & US $\$ 1$ & Yes & No \\
\hline 5 & 10 & $3 \%$ & US $\$ 1$ & Indirectly & Yes \\
\hline 6 & 10 & $3 \%$ & US $\$ 13,3$ & Yes & No \\
\hline 7 & 10 & $10 \%$ & US $\$ 1$ & Yes & No \\
\hline 8 & 10 & $10 \%$ & US $\$ 13,3$ & Yes & No \\
\hline
\end{tabular}

${ }^{\mathrm{a} N o t e}$ that all exchange rates between currencies were conducted early 2007, e.g., $1 / 1-2007,1 €=1,32$ USD.

\section{CONCLUDING REMARKS}

Fire emissions and fire toxicity are important subjects that have been discussed since the 1970s and studied in detail since the 1980s. In recent years, the study of fire emissions has been extended to take into account their impact on the environment. To date a standardised approach to establish the environmental impact of fires is lacking but work is underway in ISO TC92/SC3/WG6 and at the very least a standardised methodology concerning which species should be included in any quantitative assessment of the environmental impact of fires should be established in the coming years. In lieu of a standardised approach two models have been developed and tested to study the environmental impact of fire safety. Clearly complex, quantitative data concerning fire emissions are needed concerning any assessment of the environmental impact of fires. This paper has presented these models and some typical data that can be useful in an LCA.

Regulation of chemicals used in products is necessary to ensure that society is protected from hazardous substances. There are ample examples of how chemicals with desirable performance have been shown to have undesirable side-effects, e.g. DTT, PCBs just to name a few. It is, however, necessary to have a sound scientific basis for legislation before costly regulations are introduced.

Both the Fire-LCA and Fire-CBA models were developed in an effort to answer difficult questions concerning the relative merits of fire safety and the use of potentially undesirable chemicals. Both models provide a part of the answer but not the whole answer. The Fire-LCA model is able to include the benefits of a flame retardant (in terms of lessening the number and size of fires that a given product might be involved in) while also including the additional life-cycle burden incurred by the inclusion of a flame retardant in the product. Using a traditional LCA approach only the life-cycle burden of the flame retardant is included and the benefit of the flame retardant is lost. Similarly, the Fire-CBA model attempts to use a 
holistic approach to a cost-benefit assessment whereby the life-cycle costs of different choices made in the product life-cycle are taken into account in calculating an overall life-cycle cost of the product.

Table 7. Summary of data used in scenario calculations [39].

\begin{tabular}{|c|c|c|}
\hline Parameter & Value & Comment \\
\hline Cost of deca-BDE & $\begin{array}{l}\text { US\$3,80 per TV } \\
\text { set }\end{array}$ & Nominal cost for drop in technology [57] \\
\hline $\begin{array}{l}\text { Additional cost for use } \\
\text { of FR TV set }\end{array}$ & -- & $\begin{array}{l}\text { Assumed there is no additional cost for using an FR } \\
\text { TV set relative to a non-FR TV }\end{array}$ \\
\hline VSL & US\$ 5000000 & Based on CPSC data [43] \\
\hline $\begin{array}{l}\text { Average cost for } \\
\text { treatment of burn victims }\end{array}$ & US\$ 200000 & Still et al. [58] \\
\hline Discounting rate & $3 \%, 10 \%$ & $\begin{array}{l}\text { Two different discounting rates applied to test } \\
\text { sensitivity of model [43] }\end{array}$ \\
\hline TV life-cycle & $10 \mathrm{yrs}$ & Based on data from Fire-LCA model [55] \\
\hline $\begin{array}{l}\text { Number of TV sets in } \\
\text { Europe }\end{array}$ & 230 million & Estimate based on Internet penetration in EU \\
\hline Deaths avoided per year & 160 & $\begin{array}{l}\text { For the entire TV population. When TV has } 10 \mathrm{yr} \\
\text { life-cycle, } 10 \% \text { of this number is saved for each of } \\
\text { the next } 10 \text { yrs [55]. }\end{array}$ \\
\hline Injuries avoided per year & 2000 & $\begin{array}{l}\text { For the entire TV population. When TV has } 10 \mathrm{yr} \\
\text { life-cycle, } 10 \% \text { of this number is avoided for each } \\
\text { of the next } 10 \mathrm{yrs} \text { [55]. }\end{array}$ \\
\hline \# full house fires avoided & 11/million TV sets & Based on data from Fire-LCA model [55] \\
\hline Average cost per house & US\$180 000 & $\begin{array}{l}\text { Based on the average price of a house in Sweden in } \\
\text { March of } 2005\end{array}$ \\
\hline $\begin{array}{l}\text { \# TV fires avoided } \\
\text { (including house fires }\end{array}$ & $\begin{array}{l}\text { 107/million TV } \\
\text { sets }\end{array}$ & Based on data from Fire-LCA model [55] \\
\hline Average cost per fire & US\$7500 & $\begin{array}{l}\text { Based on statistics from the Swedish Insurance } \\
\text { Federation. This assumes that all fires are equal, i.e. } \\
\text { small fires and large fires are weighted equally in } \\
\text { the statistics. }\end{array}$ \\
\hline $\begin{array}{l}\text { Cost due to exposure to } \\
\text { deca-BDE }\end{array}$ & 0 & $\begin{array}{l}\text { Number of injuries or deaths due to exposure to } \\
\text { deca-BDE assumed to be zero }\end{array}$ \\
\hline
\end{tabular}

Table 8. Results from CBA calculation [39].

\begin{tabular}{|c|c|c|c|}
\hline Scenario & Gross Cost (million US\$) & Gross Benefit (million US\$) & Net Benefit (million US\$) \\
\hline 1 & 110 & 1200 & 1090 \\
\hline 2 & 110 & 1050 & 940 \\
\hline 3 & 393 & 1050 & 657 \\
\hline 4 & 110 & 1490 & 1380 \\
\hline 5 & 110 & 1210 & 1100 \\
\hline 6 & 393 & 1490 & 1097 \\
\hline 7 & 110 & 1078 & 968 \\
\hline 8 & 393 & 1078 & 685 \\
\hline
\end{tabular}

Unfortunately neither model is able to include all of the potential emissions or costs and benefits in a way that facilitates a truly objective, holistic decision concerning the pros and cons of choosing fire safety over potential environmental burden. As for all complex tools, the models are no better than their input and the quality of data across the whole life-cycle of a product is generally patchy. There is a need to improve the assessment stages of both models and to develop a global model, capable of taking into account both emissions and their impact, and the societal impact of different regulations and the cost-benefit of one choice against another. The development of such a multi-parameter tool is a difficult, but nonetheless important, task that will require a significant amount of research in the future to realise. 


\section{ACKNOWLEDGEMENTS}

The authors would like to acknowledge the instrumental work conducted by IVL Swedish Environmental Institute in the development of the Fire-LCA model. Further, the work presented here would not have been possible without the support of the laboratory staff both at SP Fire Technology and SP Chemistry and Materials Technology.

\section{REFERENCES}

[1] Suter, K.E., et al. (Guest editor), (1989) Analytical and Toxicological Investigations of Respiratory Filters and Building Ventilation Filters Exposed to Combustion Gases of the Chemical Warehouse Fire in Schweizerhalle, Chemosphere 19(7):1019-1109, http://dx.doi.org/10.1016/0045-6535(89)90524-9

[2] Ashford, N., Barrett, K., Bernstein, A., Costanza, R., Costner, P., Cranor, C., deFur, P., Geiser, K., Jordan, A., King, A., Kirschenmann, F., Lester, S., M'Gonigle, M Montague, P., Peterson Myers J., O'Brien, M., Ozonoff, D., Raffensperger, C., Regal, P., Resor, P., Robinson, F., Schettler, T., Smith, T., Sperling, K-R., Steingraber, S., Takvorian, D., Tickner, J., von Moltke, K., Wahlstrom, B. and Warledo, J., "Wingspread Statement on the Precautionary Principle", Wingspread Conference Centre, 1998, Racine, Wisconsin, USA.

[3] Albinsson, B., (1996) Accept more fires and avoid dangerous flame retardant chemicals!, Sirenen Nr 1, available in Swedish only.

[4] Andersson, P., Simonson, M., Stripple, H., and Paloposki, T., "Fire-LCA Guidelines”, SP Report 2004:43, ISBN 91-85303-21-6, 2004.

[5] Levin, B. C., (1987) A summary of the NBS Literature Reviews on the Chemical Nature and Toxicity of the Pyrolysis and Combustion Products from Seven Plastics: ABS, Nylons, Polyester, Polyethylenes, PVC and Rigid Polyurethane Foams, Fire and Materials, 11(3):143-157, http://dx.doi.org/10.1002/fam.810110304

[6] Paabo, M. and Levin, B. C., (1987) A Literature Review of the Chemical Nature and Toxicity of the Decomposition Products of Polyethylenes, Fire and Materials, 11(2):55-70, http://dx.doi.org/10.1002/fam.810110203

[7] Braun, E. and Levin, B. C., (1987) Nylons: A Review of the Literature on Products of Combustion and Toxicity, Fire and Materials, 11(2):71-88, http://dx.doi.org/10.1002/fam.810110204

[8] Paabo, M. and Levin, B. C., (1987) A Review of the Literature on the Gaseous Products and Toxicity Generated from the Pyrolysis and Combustion of Rigid Polyurethane Foams, Fire and Materials, 11(1):1-29, http://dx.doi.org/10.1002/fam.810110102

[9] Gurman, J. L., Baier, L., and Levin, B. C., (1987) Polystyrenes: A Review of the Literature on the Products of Thermal Decomposition and Toxicity, Fire and Materials, 11(3):109-130, http://dx.doi.org/10.1002/fam.810110302

[10] Hugget, C, and Levin, B.C., (1987) Toxicity of the Pyrolysis and Combustion Products of Poly(Vinyl Chlorides): A Literature Assessment, Fire and Materials, 11(3):131-142, http://dx.doi.org/10.1002/fam.810110303

[11] Månsson, M., Dahlberg, M., Blomqvist, P., and Rydeman, A., "Combustion of Chemical Substances and Smoke Gas Components in Large-Scale Experiments”, SP Report 1994: 28, Borås, Sweden, 1995.

[12] Lönnermark, A., and Blomqvist, P.,” Emissions from Fires in Electrical and Electronics Waste”, SP Report 2005:42, Borås, Sweden, 2005.

[13] Lönnermark, A., and Blomqvist, P., “Emissions from Tyre Fires”, SP Report 2005:43, Borås, Sweden, 2005. 
[14] Smith-Hansen, L., "STEP - Combustion of chemical substances and the impact on the environment of the fire products, Final report", Risø National Laboratory, Denmark, Risø-R764(EN), Roskilde, 1994.

[15] Pedersen, K. E., and Markert, F., "Assessment of Fires in Chemical Warehouses - An Overview of the TOXFIRE Project", Risø National Laboratory, Risø-R-932(EN), Roskilde Denmark, 1997.

[16] Persson, B. and Simonson, M., (1998) Fire emissions into the atmosphere, Fire Technology, 34(3):267-279, http://dx.doi.org/10.1023/A:1015350024118

[17] Blomqvist, P., Rosell, L., and Simonson, M., "Quantification of PAH, dioxins and other chemical species in fire gases”, Proceedings of Interflam 2001, Edinburgh, Scotland, 2001, pp. 37-48.

[18] Blomqvist, P., and Simonson McNamee, M., "Estimation of $\mathrm{CO}_{2}$-emissions from fires in dwellings, schools and cars in the Nordic Countries”, SP AR 2009:13, Borås, Sweden, 2009.

[19] Marlair, G., Simonson M., and Gann, R.G., "Environmental Concerns of Fires: Facts, Figures, Questions and New Challenges for the Future”, Proceedings of Interflam 2004, Edinburgh, Scotland, 2004, pp. 325 - 327.

[20] ISO 26367-1:2011, "Guidelines for assessing the adverse environmental impact of fire effluents Part I: General.

[21] Simonson, M., and Stripple, H., "The incorporation of fire considerations in the Life-Cycle Assessment of polymeric composite materials: A preparatory study”, Proceedings of Interflam 1999, Edinburgh, Scotland, 1999, pp. 885-895.

[22] Simonson, M., Tullin, C., and Stripple, H., (2002) Fire-LCA study of TV sets with V0 and HB enclosure material, Chemosphere, 46(5):737-744, http://dx.doi.org/10.1016/S0045$\underline{6535(01) 00238-7}$

[23] Simonson, M., Andersson, P., Emanuelsson, V., and Stripple, H., (2003) A Life-Cycle Assessment (LCA) Model for Cables based on the Fire-LCA Model, Fire and Materials, 27(2):71-89, http://dx.doi.org/10.1002/fam.818

[24] Andersson, P., Blomqvist, P., Rosell, L., Simonson, M., and Stripple, H., "The environmental effect of furniture”, Proceedings of Interflam 2004, Edinburgh, Scotland, 2004, pp. 1467-1478.

[25] Simonson, M., Andersson, P., and van den Berg, M., "Cost Benefit Analysis Model for Fire Safety: DecaBDE Case Study”, Dioxin 2006, Oslo, 2006.

[26] Hirschler, M.M., (ed.), Carbon Monoxide and Human Lethality: Fire and Non-Fire Studies, ISBN 1-85861-015-X, Elsevier Science Publishers Ltd, Essex, 1993.

[27] ISO 13571:2007, "Life Threatening Components of Fire - Guidelines on the Estimation of Time Available for Escape Using Fire Data”.

[28] Hölemann H., 1994. Environmental Problems Caused By Fires And Fire-fighting Agents. Fire Safety Science 4: 61-77. http://dx.doi.org/10.3801/IAFSS.FSS.4-61

[29] Blomqvist, P., Rosell, L., and Simonson, M., (2004) Emissions from Fires part I: Fire retarded and non-Fire retarded TV-sets, Fire Technology 40(1):39-58, http://dx.doi.org/10.1023/B:FIRE.0000003315.47815.cb

[30] Blomqvist, P., Rosell, L., and Simonson, M., (2004) Emissions from Fires part II: Simulated Room Fires, Fire Technology 40(1):59-74, http://dx.doi.org/10.1023/B:FIRE.0000003316.63475.16

[31] Andersson, P., Rosell, L., Simonson, M., and Emanuelsson, V., (2004) Small and large scale fire experiments with electric cables under well-ventilated and vitiated conditions, Fire Technology 40(3):247, http://dx.doi.org/10.1023/B:FIRE.0000026879.07753.86 
[32] Blomqvist, P., and Simonson McNamee, M., "Large-scale generation and characterization of fire effluents” in Fire Toxicity, Stec A. and Hull R. (ed.), Woodhead Publishing Ltd, London 2010, p.461-514.

[33] ISO 14040:2006, "Environmental management - Life cycle assessment - Principles and framework".

[34] ISO 14044:2006, "Environmental management - Life cycle assessment - Requirements and guidelines".

[35] ISO 14040:1997, "Environmental management - Life cycle assessment - Principles and framework".

[36] ISO 14041:1998, "Environmental management - Life cycle assessment - Goal and scope definition and inventory analysis".

[37] ISO 14042:2000, "Environmental management - Life cycle assessment - Life cycle impact assessment”.

[38] ISO 14043:2000, "Environmental management - Life cycle assessment - Life cycle impact interpretation”.

[39] Simonson, M., Andersson, P., and van den Berg, M., "Cost Benefit Analysis Model for Fire Safety, Methodology and TV (DecaBDE) Case Study”, SP Report 2006:28, Borås, Sweden, 2006.

[40] Revesz, R.L., (1999) Environmental Regulation, Cost-Benefit Analysis, and the Discounting of Human Lives, Columbia Law Review, 99(4):941-1017, http://dx.doi.org/10.2307/1123481

[41] Seligman, D., (1986) How much money is your life worth?, Fortune, 113(5):25-28.

[42] Blomquist, G.C., (2004) Self-Protection and Averting Behavior, Values of Statistical Lives and Benefit Cost Analysis of Environmental Policy, Review of Economics of the Household, 2(1):89110, http://dx.doi.org/10.1023/B:REHO.0000018024.53114.3a

[43] Smith, C.L., "Preliminary regulatory analysis of a draft proposed rule to address cigarette and small open flame ignitions of upholstered furniture”, Directorate for Economic Analysis, US CPSC, November 2005.

[44] Ashenfelter, O., and Greenstone, M., "Using Mandated Speed Limits to Measure the Value of a Statistical Life", presented at the session in honor of the memory of Sherwin Rosen at the AERE/ASSA meetings, available as NBER Working Paper 9094, 2002.

[45] Jenkins, R.R., Owens, N., and Wiggins, L.B., (2001) Valuing reduced risk to children: The case of bicycle safety helmets, Contemporary Economic Policy 19(4):397-408, http://dx.doi.org/10.1093/cep/19.4.397

[46] Blomquist, G.C., Miller, T.R., and Levy, D.T., (1996) Values of risk reduction implied by motorist use of protection equipment: New evidence from different populations, Journal of Transport Economics and Policy 30:55-66.

[47] Carlin, P.S. and Sandy, R., (1991) Estimating the value of a young child's life, Southern Economic Journal, 58(1):186-202, http://dx.doi.org/10.2307/1060042

[48] Mount, T., Weng, W., Schulze, W., and Chestnut, L., "Automobile safety and the Value of Statistical Life in the family: Valuing reduced risk for children, adults and the elderly", Presented at the Assoc. of Environ. and Resource Economists Workshop, "Assessing and Managing Environmental and Public Health Risks”, Bar Harbor, ME, June 13-15, 2001.

[49] Dreyfus, M.K. and Viscusi, W.K., (1995) Rates of time preference and consumer valuation of automobile safety and fuel efficiency, Journal of Law and Economics, 38(1):79-105, http://dx.doi.org/10.1086/467326 
[50] Atkinson, S.E. and Halvorsen, R., (1990) The valuation of risks to life: Evidence from the market for automobiles, Review of Economics and Statistics 72(1):133-136, http://dx.doi.org/10.2307/2109748

[51] Gayer, T., Hamilton, J.T., and Viscusi, W.K., (2000) Private values of risk tradeoffs at superfund sites: Housing market evidence on learning about risk, Review of Economics and Statistics, 82(3):439-451, http://dx.doi.org/10.1162/003465300558939

[52] Andersson, P., Simonson, M., Rosell, L., Blomqvist, P., and Stripple, H., "Fire-LCA model: Furniture Study”, SP Report 2003:22, Borås, Sweden, 2003.

[53] Simonson, M., Andersson, P., Rosell, L., Emanuelsson, V., and Stripple, H., "Fire-LCA model: Cables case study”, SP Report 2001:22, Borås, Sweden, 2002.

[54] Andersson, P., Simonson, M., Blomqvist, P., Rosell, L., and Stripple, H., "Fire-LCA Model: Cable case study II - NHXMH and NHMH cable”, SP Report 2005:45, Borås, Sweden, 2005.

[55] Simonson, M., Blomqvist, P., Boldizar, A., Möller, K., Rosell, L., Tullin C., Stripple, H., and Sundqvist, J.O., “Fire-LCA model: TV case study”, SP Report 2000:13, Borås, Sweden, 2001.

[56] Hamzi, R., Londiche H., and Bourmada, N., (2008) Fire-LCA Model for Environmental Decision Making, Chem. Eng. Research and Design 86(10):1161-1166, http://dx.doi.org/10.1016/j.cherd.2008.05.004

[57] Stevens, G.C., and Mann, A.H., "Risks and Benefits in the Use of Flame Retardants in Consumer Products”, A report for the Department of Trade and Industry, DTI Ref: URN 98/1026, 1999.

[58] Still, J., Orlet, H., Law, E., and Gertler, C., (2000) Lawn Mower Related Burns, J. Burn Care \& Rehabilitation, 21(5): 403-405, http://dx.doi.org/10.1097/00004630-200021050-00002 